\title{
Cognitive Stimulation Therapy (CST) for dementia: A systematic review of
}

\section{qualitative research}

Luke Gibbor $^{\mathrm{a}}$, Lauren Yates ${ }^{\mathrm{a}}$, Anna Volkmer ${ }^{\mathrm{b}}$, and Aimee Spector ${ }^{\mathrm{a}}$

${ }^{a}$ Department of Clinical, Educational and Health Psychology, University College

London, London, UK; ${ }^{b}$ Department of Psychology and Language Sciences, University

College London, London, $U K$

Corresponding Author: Luke Gibbor, luke.gibbor.11@ucl.ac.uk

E-mail addresses: lauren.yates@ucl.ac.uk, a.spector@ucl.ac.uk, a.volkmer.15@ucl.ac.uk

\section{Funding}

This project was supported by University College London as part of a Doctorate in Clinical Psychology thesis.

\section{Disclosure statement}

The authors report no conflict of interest. 


\begin{abstract}
Introduction: Cognitive Stimulation Therapy (CST) is a well-established intervention for people with dementia shown to improve cognition and quality of life. Past research includes development of a longer term 'maintenance CST' and an individual CST programme. Previous reviews of CST have focused on quantitative outcomes or excluded certain formats of CST. This review aimed to fill this gap by evaluating how the voices of facilitators, carers and people with dementia in qualitative studies of CST can contribute to our understanding of its implementation and how it is experienced.
\end{abstract}

Methods. The current systematic review explored the experience and perspectives of people with dementia, facilitators and carers. Thematic Analysis (Braun and Clarke, 2012) was used to analyse this data, alongside Thomas and Harden's (2008) guidance on synthesising qualitative findings.

Results. A systematic literature search retrieved 10 relevant studies using qualitative methodology. Eighteen themes were generated, which were grouped into three categories: 'Acceptability and feasibility', 'Features of CST' and 'Key outcomes'. Conclusions. To our knowledge, this is the only review to explore solely qualitative studies of CST. Findings provided insight into the shared features, outcomes and factors affecting implementation, and suggested theories for discrepancies between quantitative and qualitative findings in the literature. Some of the common themes were also in keeping with past reviews.

\title{
Key Words:
}

Cognitive stimulation therapy, dementia, systematic review, qualitative studies 


\section{Introduction}

There is ongoing emphasis on early intervention for people with dementia (PWD) and interventions providing 'cognitive stimulation' have been particularly wellsupported (Olzarán et al. 2010; McDermott et al. 2019). Previously, 'cognitive stimulation' has been used interchangeably when describing approaches consisting of cognitive ‘training', 'stimulation' or 'rehabilitation'. However, Clare and Woods (2004, p. 387) offered the definition of cognitive stimulation as "engagement in a range of group activities and discussions aimed at general enhancement of cognitive and social functioning" to distinguish between them.

\section{Cognitive Stimulation Therapy for Dementia}

Cognitive Stimulation Therapy (CST) (Spector et al. 2003) is a well-established intervention for people with mild to moderate dementia. It emphasises use of multisensory stimulation and implicit learning, and encourages 'personhood' (Kitwood, 1997) and the use of cognitive skills within a social setting. The positive impact of CST on cognition and quality of life has been extensively supported (Aguirre, Woods, Spector \& Orrell, 2012; Spector et al. 2003; Woods, Aguirre, Spector \& Orrell, 2012), and it was shown to be cost-effective (Knapp et al. 2006). CST is also the only psychosocial intervention recommended to improve cognition for people with mild to moderate dementia by the National Institute of Health and Clinical Excellence (NICE, 2018). Following its wide-spread success in the UK, there has also been an increase in cultural adaptation and use of CST internationally (Lobbia et al. 2018).

Longer-term maintenance CST (MCST) was developed to investigate whether these benefits could be retained. Research suggested continued improvements to quality of life 
and activities of daily living, but no significant benefit to cognition. However, findings suggested greater improvement to cognition when it was combined with anticholinesterase inhibitor treatment (Orrell et al. 2014). An individual cognitive stimulation therapy (iCST) programme has also been evaluated (Yates, Orrell, Spector \& Orgeta, 2015), based on CST and MCST and designed to be delivered by family caregivers in the community. Findings suggested improvements in the caregiving relationship from PWD's perspective, but no change in cognition and quality of life for PWD (Orrell et al. 2017).

\section{Systematic Reviews of CST}

CST has also been supported by a range of systematic reviews, which indicated benefits to cognition, quality of life and wellbeing (Lobbia et al. 2018; Woods et al., 2012). Although these provided important evidence on the efficacy of intervention, qualitative studies provide better understanding of the experiences of those involved. Of note, few qualitative studies of CST have been conducted, despite qualitative research being recommended and important in providing valuable insight into the development and refinement of complex interventions (Medical Research Council, 2008).

Dugmore, Orrell and Spector (2015) conducted a review of qualitative studies of psychosocial interventions, noting their ability to "draw together insights" from PWD, staff and carers. They found several factors that may have influenced psychosocial interventions, including the skills and beliefs of PWD and their carers, and the importance of empathy, flexibility and creativity in facilitators.

More recently, Toh, Ghazali and Subramaniam (2016) conducted a review of the usefulness and effectiveness of CST, excluding maintenance CST. They concluded that 
CST is effective, though there were inconsistencies when comparing quantitative and qualitative findings. They suggested quantitative measures may not be sensitive enough to detect effects that qualitative feedback could discover.

\section{The current review}

Current systematic reviews of CST have mostly focused on quantitative studies, whilst those exploring qualitative data had a broader focus on psychosocial interventions or excluded certain formats of CST or more recent cultural adaptations. The current review aimed to attend to this gap and consider qualitative studies of CST, MCST, iCST and those published internationally. It is the first review to consider qualitative findings across all formats of CST from the perspectives of facilitators, PWD and their carers. The key research questions were: What do qualitative studies on CST reveal about (a) its acceptability and feasibility (b) its key features and (c) its effects?

\section{Methods}

\section{Search Strategy}

A systematic literature search was conducted in January 2019. PsychInfo, EMBASE, MEDLINE, CINAHL and Web of Science databases were selected as major healthcare databases covering a range of professional disciplines, which ensured that the search was comprehensive. Two of the authors, who were involved in the original development of CST and iCST, were consulted about additional articles that may be relevant. Search terms relating to dementia were combined with terms associated with CST (see Appendix A). 


\section{Selection Criteria}

All studies dating prior to 2003 were excluded as they were published before the development of CST (Spector et al., 2003). Studies were then required to meet the following criteria:

- Involve a primary focus on CST, MCST, iCST or cultural adaptations of CST

- Employ qualitative or mixed methodology to ensure that that all relevant qualitative data were considered for inclusion in the review

- Include formal interview processes (e.g. focus group or individual interview) and provide sufficient qualitative data to contribute to the review

- Published in English

Studies meeting these criteria were retrieved for more detailed evaluation. The search process is illustrated in Figure 1.

[INSERT FIGURE 1 NEAR HERE]

\section{Quality appraisal}

Study quality was assessed using the Critical Appraisal Skills Programme Qualitative Checklist (CASP-QC) (CASP, 2018). Quality was established as a score indicating how many of the 10 criteria were met. Appraisal was first conducted by the lead author (LG) for four randomly selected studies from those shortlisted, and subsequently by a second rater, AV. Due to limitations in binary outcomes on the checklist, allocation of 'half' points was agreed. If there was not enough information in the article to decide on a criterion, it was marked 'Can't tell' and allocated no points. Disagreements about ratings within the four articles were discussed, and discussion points were used to establish a baseline for meeting criteria when rating the remaining articles included in the review. After rating all included papers, any paper with a score 
more than two standard deviations lower than the mean were to be excluded from analysis.

\section{Method of analysis}

Thematic Analysis (Braun \& Clarke, 2012) was used to analyse articles in this review, with additional guidance on synthesising qualitative research from Thomas and Harden (2008). For the purposes of this review, only quotes and themes given in 'results' were considered data. Firstly, studies were read in full, to allow familiarisation with the data. 'Results' from each study were then re-read, and inductively coded lineby-line to construct an initial set of descriptive themes. Extracts for each theme were then reviewed separately for their relevance to the study questions, and the coding system was further refined. This was an iterative process resulting in a hierarchy of descriptive themes and sub-themes that contributed to each review question. The themes, alongside extracts, were reviewed by two members of the research team, LY and AS, to reach a consensus on theme descriptions and structure of the hierarchy. The papers were then re-read to establish if any further data was available and relevant.

\section{Results}

The literature search retrieved 734 results once duplicates were removed. Titles and abstracts of studies were read and compared with inclusion and exclusion criteria. The final review included nine peer reviewed articles and one doctoral thesis identified through consultation with co-authors, in total including 102 PWD, 133 carers and 84 facilitators (see summary of articles and demographics in Table 1). 


\section{Quality Analysis}

Seven studies employed purely qualitative design (Aguirre, Spector, Streater, Burnell \& Orrell, 2011; Bertrand et al. 2018; Dickinson, Gibson, Gotts, Stobbart \& Robinson, 2017; Leung, Yates, Orgeta, Hamidi \& Orrell, 2017; Spector, Gardner \& Orrell, 2011; Streater, 2015; Yates et al. 2015). Three studies used mixed methodology (Bailey, Kingston, Alford, Taylor \& Tolhurst, 2017; Kelly et al. 2017; Wong, Yek, Zhang, Lum \& Spector, 2018). On average, included articles met 7.5 out of 10 quality criteria, with a range of 4.5 to 9 . No shortlisted studies fell below two standard deviations from the mean. However, no studies reflected on the impact of researcher identity on the process, nor utilised respondent validation to support the credibility of findings, and six studies did not clearly justify their chosen methodology. One study reflected on the relationship between members of a focus group (Aguirre et al. 2011).

\section{[INSERT TABLE 1 HERE]}

\section{Description of Themes}

The analysis generated three overarching themes which contributed to the research questions: 'Acceptability and feasibility', 'Features of CST' and 'Key outcomes'. Eighteen sub-themes were generated, and the hierarchy of themes and sources are summarised within Table 2. Where appropriate, ellipsis (...) have been used to isolate relevant quotation.

[INSERT TABLE 2 HERE] 


\section{Acceptability and feasibility}

Fitting service needs. Bertrand et al. (2018) described how treatment options for dementia are not well known in Brazil, with little offered following diagnosis. Comparatively, facilitators in the UK understood CST to be evidence-based and contributing to care beyond other psychosocial interventions, which was associated with managers' motivation to provide CST (Dickinson et al. 2017). Similarly, facilitators found MCST easy to run, but were concerned that the programme length meant others could not be offered sessions (Streater, 2015).

"If we hadn't been doing the long programme, we could have got other new people in... making the waiting list shorter." (Facilitator) (ST)

\section{Facilitators and barriers.}

Carer engagement. Attendance to sessions relied on carers transporting PWD to groups, meaning those without a carer may have no means of accessing them (Streater, 2015), and was associated with financial and time cost (Bertrand et al. 2018).

“...if you can't provide transport... unless they've got a really well motivated carer, they are not going to get there." (Facilitator) (ST)

Carers felt CST was worth travelling for (Kelly et al. 2017), but could feel frustrated when they heard little about the content of sessions (Spector et al., 2011), whilst providing entertainment or psychoeducation for carers may encourage engagement (Bertrand et al. 2018).

Resources. Facilitators of all formats of CST reported the value and availability of resources in manuals, which were important aids for facilitation (Aguirre et al., 2011; 
Streater, 2015; Yates et al. 2015), though some suggestions in the MCST manual were experienced as less appropriate. However, additional necessary resources were highlighted, including people, time, and physical resources such as equipment and rooms needed to run sessions (Dickinson et al. 2017; Kelly et al. 2017).

'It's a huge volume of work... you've got to have the resources; people, time and the practical things that you take to the different sessions". (Facilitator) (D) In particular, time was experienced as a barrier to facilitation by carers delivering iCST (Leung et al. 2017), and PWD expressed concern that carers would not have sufficient time to do activities with them (Yates et al. 2015).

"We might have had a problem with identifying the time to sit down and organise ourselves." (Carer) (L)

Training and experience. Facilitators recognised training as crucial for engaging facilitators, as it demystified the intervention, and supervision and experience of working with dementia supported adequate facilitation (Dickinson et al. 2017). Appropriate communication skills, and support from others was also seen as very important both by professionals and family carers delivering the intervention (Streater et al., 2015; Leung et al. 2017). Further, carers wondered if iCST would be best delivered by professionals or an “outsider" (Yates et al. 2015).

"I think you can be too close. I feel you should, you need to be detached, a little bit, and I couldn't be detached..." (Carer) $(Y)$

Patient motivation. Carers and facilitators associated lower patient motivation with increased difficulty getting PWD to groups (Bertrand et al. 2018), and motivation was difficult to retain during MCST (Streater, 2015).Family carers delivering iCST 
found motivation could fluctuate (Yates et al.2015) and was linked to emotional and physical health problems of PWD (Leung et al. 2017).

“...when he was reluctant, and I suppose that was also tied to him having an emotional response to his condition." (Carer) (L)

\section{Features of CST}

Mental stimulation. PWD felt it encouraged concentration, reflection and alertness, as 'if you do not use it, you lose it', whilst carers suggested it kept PWD in the present and supported learning (Leung et al. 2017). However, whilst PWD experienced mental stimulation as meaningful, they also felt they depended on others to provide it (Yates et al.2015).

“... I believe that we are all crying out for help and stimulation, but we can't, haven't so much got ideas in our own head as we hope other people can encourage us." $(P W D)(Y)$

However, some carers were less enthusiastic about mental stimulation (Bertrand et al., 2018) or felt less confident in its benefits (Aguirre et al. 2011).

Adaptability. Carers felt adaptability and flexibility within CST allowed better engagement of PWD (Bailey et al. 2017). Facilitators and carers spoke about the importance of choice, emphasising not asking PWD to do something they are unable to (Aguirre et al. 2011), and recognised that PWD may have little interest in certain topics or sessions (Streater, 2015; Wong et al. 2018). Facilitators also felt adaptability helped manage groups of people with different stages of dementia and allowed a person-centred approach (Dickinson et al. 2017). 
"The books don't always fit the pattern. I suppose the book is giving you guidance to what the activities are, but then just have to adjust that to the patients' level of concentration, physical health or mobility." (Facilitator) (D)

Being with others. Overall, PWD and carers felt being with others offered opportunities to be heard, share memories, and gain other perspectives on matters (Aguirre et al. 2011; Leung et al. 2017; Spector et al. 2011). Carers, facilitators and PWD recognised the opportunities for socialising in group CST (Bailey et al. 2017; Bertrand et al. 2018; Dickinson et al. 2017). Further, PWD could help and support each other alongside facilitators (Bertrand et al. 2018; Spector et al. 2011), and a shared identity and experience of dementia meant PWD could feel safe in taking part (Bailey et al. 2017).

“... People who are suffering with the same memory losses, my mum doesn't feel so scared to make a fool of herself or things like that." (Carer) (BA).

Comparatively, carers felt the structure of iCST encouraged communication with PWD (Leung et al. 2017), who felt sessions provided opportunities for novel conversations and discussion. In addition, PWD also found that iCST gave them the assistance needed to do activities at home (Yates et al. 2015).

Practical activities. Wong et al. (2018) observed a preference in Chinese PWD for practical tasks, which was mirrored by a culture non-specific desire for outdoor and physical activities (Aguirre et al. 2011; Leung et al. 2017) and keeping the body active was seen as important as the mind (Yates et al., 2015).

"I like making things with my hands, just to keep my mind stimulated."

$$
(P W D)(L)
$$


Relaxed environment. PWD felt a supportive and friendly environment, as well as kindness and providing "human courtesies" was important (Aguirre et al. 2011; Spector et al. 2011).

"Nothing that involves cruelty. As long as there's kindness you can't fault it." (PWD) (A)

Similarly, facilitators tried to ensure group composition avoided conflict and encouraged a supportive environment (Dickinson et al. 2017), and carers felt iCST might require a more "formal setting" but felt this was manageable with the right approach (Yates et al. 2015).

Difficulty of Sessions. The difficulty of sessions was raised in both group and individual formats. Some PWD struggled with tasks as their abilities declined, which made facilitation harder (Streater, 2015), whilst others found difficult tasks more acceptable (Kelly et al. 2017). Conversely, carers and PWD could sometimes experience activities as 'childish' or too easy in both group and iCST (Leung et al. 2017; Streater, 2015), though carers saw that activities could be enjoyable once started (Bailey et al. 2017; Yates et al. 2015).

“...the first week [name] said it was a bit childish, but he has carried on and he has come, and he enjoyed it..." (Carer) (BA)

\section{Key outcomes}

Cognition. Most studies described a positive impact on cognition (Bailey et al., 2017; Kelly et al., 2017; Leung et al., 2017; Spector et al., 2011; Streater, 2015; Yates et al., 2015) from the view of all participant groups. Respondents, including PWD, referred to specific improvements in attention and concentration, some of which connected this 
with a related sense of alertness (Kelly et al., 2017; Leung et al., 2017; Spector et al., 2011; Streater, 2015).

"I found it great, it kept me focused in the right direction. It helped me to learn ways of ... improving my memory.” (PWD) (K)

Similarly, carers and PWD reported improvement to memory in retaining new information and events, spontaneous verbal fluency (Spector et al., 2011), non-specific memory improvements, and new ways to improve memory which were maintained over time (Kelly et al., 2017).

"Yes, remembering the recent events have been a lot more simple and a lot more logical than it was, certainly." (PWD) (SP)

However, some carers perceived minimal, or non-sustainable improvement (Bailey et al. 2017).

Confidence. Facilitators, carers and PWD all observed improved confidence in PWD, which was associated with reduction in anxiety and improved self-esteem, confidence outside of the group setting, and participants being more vocal (Aguirre et al. 2011; Bailey et al. 2017; Dickinson et al. 2017; Kelly et al., 2017; Leung et al. 2017; Spector et al. 2011; Streater, 2015).Carers and PWD also felt a positive change in PWD's relationship to their diagnosis and associated difficulties (Bailey et al. 2017; Kelly et al. 2017; Leung et al. 2017)

"I don't get frustrated with myself anymore. When I forget something, Ijust relax and then it comes back to me." (PWD) (K)

Enjoyment. CST appeared to provide a general sense of enjoyment reflected by all participant groups (Bailey et al. 2017; Kelly et al. 2017; Leung et al. 2017; Spector et al. 2011; Streater, 2015). PWD reported looking forward to CST each week and were 
sorry to end the group (Spector et al. 2011), and felt the sense of enjoyment persisted beyond memory of iCST sessions (Leung et al. 2017)

"Yeah even though like things might not stay with me ..., but it's brilliant." $(P W D)(L)$

Mood. Carers observed PWD being in better mood following intervention (Kelly et al. 2017; Yates et al. 2015; Streater, 2015) and PWD described feeling more relaxed (Spector et al., 2011). Bailey et al. (2017) associated improved mood with increased activity at home, and better communication with others. Likewise, facilitators described improved self-esteem in PWD (Dickinson et al. 2017).

“After the sessions, she came out to me a brighter, happier person." (Carer)

$(K)$

Wong et al. (2018) suggested PWD gained a sense of success and happiness through recognition of attendance, and Leung et al. (2017) found the sense of achievement was retained for PWD beyond the intervention.

Continued stimulation. Carers, facilitators and PWD felt participating in CST led to increased activity and stimulation outside of the intervention (Bailey et al. 2017; Kelly et al. 2017; Leung et al. 2017; Spector et al. 2011; Streater, 2015).

“It's made me start thinking about doing what I used to do which was painting... I think I could do more painting, and that might make me better, you know, and I can get up and do things more easily." (PWD) (L)

Carers associated this with renewed discovery of the interests of the person with dementia (Bailey et al. 2017) and observed PWD engaged in more acts of personal care and social activity (Spector et al. 2011). Leung et al. (2017) suggested CST reignited value in life and encouraged them to seek continued stimulation, and facilitators found 
individuals who participated in MCST sought greater involvement in their communities (Streater, 2015).

Relationships. Several studies observed how PWD became closer with others, both generally (Spector et al. 2011), and with their carers alongside increased conversation (Bailey et al. 2017). Carers facilitating iCST felt the structure of sessions supported them to reconcile and improve relationships with PWD (Leung et al. 2017).

“...we are interacting now, more than me trying to reach him, and me make conversation and him talk to me. He is actually talking to me first... we chat and that..." (Carer) (L)

Making a difference. Both facilitators and carers spoke about non-specific benefits of CST (Kelly et al. 2017; Spector et al. 2011), and PWD experienced CST as worthwhile (Spector et al. 2011).

“... it was just good to be able to go and discuss the things, so you felt that at least you'd done something you know I wasn't wasting my time.” (PWD) (SP)

Facilitators were also surprised at the abilities of PWD (Streater, 2015). However, some carers felt dementia is unchangeable (Leung et al., 2017).

\section{Discussion}

The current study aimed to explore what qualitative studies can reveal about the acceptability and feasibility of CST, its key features and experienced effects. Commonalities across both group and individual formats of CST were previously unidentified in the literature and may provide greater understanding of core processes independent of CST format.

\section{Interpretations and Comparisons}




\section{Acceptability and Feasibility}

Resources contained within the CST manuals were perceived as helpful, important and sufficient for facilitating intervention (Aguirre et al. 2011; Dickinson et al. 2017; Streater, 2015; Yates et al. 2015). However, findings highlighted the additional resources necessary to effectively implement CST, including time, physical resources and availability of facilitators. These requirements may result in fewer groups being offered by services. Additionally, several studies raised the importance of facilitators having enough experience and communication skills to facilitate the intervention (Dickinson et al. 2017; Leung et al. 2017; Streater, 2015). This is in keeping with past reviews of psychosocial interventions that found skills and qualities of facilitators affected implementation (Dugmore et al. 2015). Findings also identified the importance of carer engagement, especially for PWD relying on them to access groups, or for facilitating iCST. In particular, Bertrand et al.'s (2018) suggestion of provision of activity for carers whilst they wait for services may address this.

\section{Features of CST}

'Being with others' was widely represented and was not only identified in group CST but also in iCST. This suggests sessions with carers could be experienced as additional or of different quality to other interactions with them. Of interest, being with others in iCST was associated with opportunities to be heard and encouraged communication between PWD and others. These benefits may have mediated improvements in relationships with caregivers identified by quantitative outcomes in iCST (Orrell et al. 2017). Comparatively, findings suggested how dynamics in the group, such as friendliness and a sense of safety, could be important to PWD and may be associated to the shared experience inherent in group CST. 
Adaptability was also broadly reported and is in keeping with the emphasis on choice within the CST manuals. Findings suggested facilitators are responsible for adjusting difficulty and content of sessions to patients' abilities and needs. Of note, whilst difficult sessions could make facilitation harder (Streater, 2015), easier sessions resulted in poorer reactions (Bailey et al. 2017; Leung et al. 2017; Streater, 2015), emphasising the need for adaptation both whilst planning and during sessions. Wey (2006) wrote about the zone of proximal development and scaffolding (Vygotsky, 1978) in dementia rehabilitation, referring to the difference between what someone can do without help and what is possible with encouragement, support and guidance. Therefore, with appropriate support, harder tasks may offer greater challenge and stimulation to PWD, whilst easier sessions could still hold value by providing enjoyment (Bailey et al. 2017; Yates et al. 2015).

\section{Key Outcomes}

Qualitative findings suggested improvement in cognition associated with all CST formats. This was in keeping with past reviews of CST (Orrell et al. 2014; Spector et al. 2003; Woods et al. 2012) though it was discordant with quantitative findings from iCST (Orrell et al. 2017). Findings offered several theories that may explain this discrepancy. Firstly, benefits to concentration and alertness are reported across formats (Kelly et al. 2017; Leung et al. 2017; Spector et al. 2011; Streater, 2015) which are not typically measured extensively by outcomes in dementia research and changes may therefore be too small to be detectable by currently used tools. Alternatively, perceived cognitive benefit may be associated with the reported improvements to confidence and positive shift in relationship to diagnosis, alongside perception of cognitive impairment as less limiting or less significant (Bailey et al. 2017; Kelly et al. 2017; Leung et al. 2017). For 
example, Kelly et al. (2017) found no objective change in cognition despite

improvements in self-rated subjective cognitive function and satisfaction with cognitive performance. Likewise, facilitators could feel surprised at the capabilities of PWD and these modified beliefs may also be linked to perceived cognitive improvement. The benefits to relationship with others described previously, better understanding of dementia, and improved communication could also allow PWD to express themselves more frequently. This is especially important when we consider the high level of unmet needs in those both living at home and in residential care (Black et al. 2013; Hancock, Woods, Challis \& Orrell, 2006). Additionally, this could reduce levels of malignant social psychology (behaviours that undermine personhood) and thereby increase personcentred care and subsequent wellbeing for PWD (Kitwood, 1997).

A general sense of enjoyment was also experienced, which likely contributed to improvements in mood reported in several studies. Further, not only carers, but also PWD and facilitators observed interest and drive for continued stimulation and more activity following intervention, independent of the format of CST, which suggest there may be benefits for PWD in terms of longer-term improvement in stimulation and engagement with others.

\section{Strengths and Limitations}

The review was limited by availability of qualitative studies evaluating CST, indicating a need for further qualitative research in this field. Several studies were als excluded from analysis as they did not provide sufficient quantity and clarity of data to contribute to the review, notably in cultural adaptation studies. However, this was somewhat moderated by the range of quantitative studies contributing to our understanding of findings. Further, included studies were mostly of high quality, 
although the CASP was limited by the breadth of the questions which were sometimes difficult to interpret. This was minimised by using a second rater to agree a baseline for each criterion, but future research may benefit from consideration of other appraisal tools. In addition, a limitation of the current study was that studies were given equal weight for analysis, regardless of study quality.

\section{Implications for Research and Practice}

Firstly, findings highlighted a need for more qualitative research in this field, particularly involving PWD as it provides them with a sense of worth and personhood through seeking their opinion and perspectives (Bell \& Troxel, 2001; Jonas-Simpson, 2001). Further, research quality would benefit from consideration of the relationship between researcher identity and analysis. It would also benefit from more explicit justification of the methods chosen and the use of respondent validation could add to the validity of findings.

Second, understanding gained in relation to facilitators and barriers provides several recommendations for how services could optimise delivery of CST. For example, ensuring a necessary level of training and supervision to facilitate groups or individual sessions. Further, providing training in iCST, not only to carers of people unsuitable for groups, could support continued stimulation This would provide psychoeducation to carers as suggested by Bertrand et al. (2018), and may also address carers' frustration at hearing little about content of sessions (Spector et al. 2011).

Third, the common factors identified may benefit future developments by informing which components of CST might maximise efficacy or acceptability. This is particularly relevant for services unable to implement the entirety of CST manuals, for example 
those limited by staff availability. Further, the resources beyond the manuals necessary for implementation should be considered, including time for facilitators both in preparation and in delivering sessions. This may be easier for services who can re-utilise resources but is an important consideration for carers delivering iCST at home.

Qualitative findings can also aid in directing research towards appropriate outcome measures, and future studies may benefit from more specifically assessing outcomes identified in this review. One possibility is use of Likert scales as utilised by Kelly et al. (2017) to quantitatively record changes, for example in confidence, alertness and concentration.

\section{Conclusion}

CST is experienced as broadly acceptable, feasible and beneficial by PWD, their carers, and facilitators of the intervention. There are several common features across different formats of CST, which may correspond with common processes underlying the improvements reported in both quantitative and qualitative studies. This review has drawn together qualitative findings which contributes to our understanding of these processes and suggests possible guidelines for services and carers wanting to deliver CST in services or at home. These findings also provide information for researchers aiming to further develop CST and explore its efficacy. 


\subsection{References}

Aguirre, E., Hoare, Z., Streater, A., Spector, A., Woods, B., Hoe, J., \& Orrell, M. (2012). Cognitive stimulation therapy (CST) for people with dementia-who benefits most? https://doi.org/10.1002/gps.3823

Aguirre, E., Spector, A., Streater, A., Burnell, K., \& Orrell, M. (2011). Service users’ involvement in the development of a maintenance cognitive stimulation therapy (CST) programme: A comparison of the views of people with dementia, staff and family carers. Dementia, 10(4), 459-473.

https://doi.org/10.1177/1471301211417170

Bailey, J., Kingston, P., Alford, S., Taylor, L., \& Tolhurst, E. (2017). An evaluation of Cognitive Stimulation Therapy sessions for people with dementia and a concomitant support group for their carers. Dementia, 16(8), 985-1003. https://doi.org/10.1177/1471301215626851

Bell, V., \& Troxel, D. (2001). Spirituality and the person with dementia - a view from the field. Alzheimer's Care Today, 2(2), 31-45.

Bertrand, E., Naylor, R., Laks, J., Marinho, V., Spector, A., \& Mograbi, D. C. (2018). Cognitive stimulation therapy for brazilian people with dementia: Examination of implementation' issues and cultural adaptation. Aging \& Mental Health, NoSpecified. https://doi.org/http://dx.doi.org/10.1080/13607863.2018.1488944

Beuscher, L., \& Grando, V. T. (2009). Challenges in conducting qualitative research with individuals with dementia. Research in Gerontological nursing, 2(1), 6-11. 
Black, B. S., Johnston, D., Rabins, P. V., Morrison, A., Lyketsos, C., \& Samus, Q. M. (2013). Unmet needs of community-residing persons with dementia and their informal caregivers: Findings from the maximizing independence at home study. Journal of the American Geriatrics Society, 61(12), 2087-2095. https://doi.org/10.1111/jgs.12549

Braun, V., \& Clarke, V. (2012). Thematic Analysis.

Clare, L., \& Woods, R. T. (2004). Cognitive training and cognitive rehabilitation for people with early-stage Alzheimer's disease: A review. Neuropsychological rehabilitation, 14(4), 385-401.

Craig, P., Dieppe, P., Macintyre, S., Michie, S., Nazareth, I., Petticrew, M., \& Medical Research Council Guidance. (2008). Developing and evaluating complex interventions: the new Medical Research Council guidance. BMJ (Clinical Research Ed.), 337(September), a1655. https://doi.org/10.1136/bmj.a1655

Critical Appraisal Skills, \& Programme. (2018). Critical Appraisal Skills Programme. CASP Qualitative Checklist. Date accessed: 16th October 2018, (2018). https://doi.org/10.1007/978-81-322-2743-4_32

Dickinson, C., Gibson, G., Gotts, Z., Stobbart, L., \& Robinson, L. (2017). Cognitive stimulation therapy in dementia care: Exploring the views and experiences of service providers on the barriers and facilitators to implementation in practice using Normalization Process Theory. International Psychogeriatrics, 29(11), 1869-1878. https://doi.org/10.1017/S1041610217001272 
Dugmore, O., Orrell, M., \& Spector, A. (2015). Qualitative studies of psychosocial interventions for dementia: a systematic review. Aging \& mental health, 19(11), 955-967.

Hancock, G. A., Woods, B., Challis, D., \& Orell, M. (2006). The needs of older people with dementia in residential care. International Journal of Geriatric Psychiatry, 2l(1), 43-49. https://doi.org/10.1002/gps.1421

Jonas-Simpson, C. (2001). From silence to voice: knowledge, values, and beliefs guiding healthcare practices with persons living with dementia. Nursing Science Quarterly, 14(4), 304-310. https://doi.org/10.1177/08943180122108607

Kelly, M. E., Finan, S., Lawless, M., Scully, N., Fitzpatrick, J., Quigley, M., ... Devane, A. (2017). An evaluation of community-based cognitive stimulation therapy: A pilot study with an Irish population of people with dementia. Irish Journal of Psychological Medicine, 34(3), 157-167. https://doi.org/10.1017/ipm.2016.23

Kitwood, T. (1997). The experience of dementia. Aging \& Mental Health, 1(1), 13-22. https://doi.org/10.1080/13607869757344

Knapp, M., Thorgrimsen, L., Patel, A., Spector, A., Hallam, A., Woods, B., \& Orrell, M. (2006). Cognitive stimulation therapy for people with dementia: cost-effectiveness analysis. British Journal of Psychiatry, 188(6), 574-580. https://doi.org/10.1192/bjp.bp.105.010561

Leung, P., Yates, L., Orgeta, V., Hamidi, F., \& Orrell, M. (2017). The experiences of people with dementia and their carers participating in individual cognitive 
stimulation therapy. International Journal of Geriatric Psychiatry, 32(12), e34e42. https://doi.org/10.1002/gps.4648

Lobbia, A., Carbone, E., Faggian, S., Gardini, S., Piras, F., Spector, A., \& Borella, E. (2018). The efficacy of cognitive stimulation therapy (CST) for people with mildto-moderate dementia: A review. European Psychologist.

McDermott, O., Charlesworth, G., Hogervorst, E., Stoner, C., Moniz-Cook, E., Spector, A., ... Orrell, M. (2019). Psychosocial interventions for people with dementia: a synthesis of systematic reviews. Aging \& Mental Health, 23(4), 393-403. https://doi.org/10.1080/13607863.2017.1423031

NICE (2018) Dementia: assessment, management and support for people living with dementia and their carers. Retrieved from http://www.nice.org.uk/guidnace/ng97

Olzarán, J., Reisberg, B., Clare, L., Cruz, I., Peña-Casanova, J., Del Ser, T., ... \& Spector, A. (2010). Nonpharmacological therapies in Alzheimer's disease: A systematic review of efficacy. Dementia and geriatric cognitive disorders, 30(2), $161-178$.

Orrell, M., Aguirre, E., Spector, A., Hoare, Z., Woods, R. T., Streater, A., ... Russell, I. (2014). Maintenance cognitive stimulation therapy for dementia: single-blind, multicentre, pragmatic randomised controlled trial. British Journal of Psychiatry, 204(6), 454-461. https://doi.org/10.1192/bjp.bp.113.137414

Orrell, M., Yates, L., Leung, P., Kang, S., Hoare, Z., Whitaker, C., ... \& Pearson, S. (2017). The impact of individual Cognitive Stimulation Therapy (iCST) on 
cognition, quality of life, caregiver health, and family relationships in dementia: A randomised controlled trial. PLoS medicine, 14(3), e1002269.

Ritchie, J., \& Spencer, L. (1993). The Analysis of Qualitative Data: An approach to analysis for applied social policy research. Analyzing qualitative data. London: Routledge.

Shankar, A., Hamer, M., McMunn, A., \& Steptoe, A. (2013). Social isolation and loneliness: relationships with cognitive function during 4 years of follow-up in the English Longitudinal Study of Ageing. Psychosomatic medicine, 75(2), 161-170.

Spector, A., Gardner, C., \& Orrell, M. (2011). The impact of Cognitive Stimulation Therapy groups on people with dementia: Views from participants, their carers and group facilitators. Aging and Mental Health, 15(8), 945-949. https://doi.org/10.1080/13607863.2011.586622

Spector, A., Thorgrimsen, L., Woods, B. O. B., Royan, L., Davies, S., Butterworth, M., \& Orrell, M. (2003). Efficacy of an evidence-based cognitive stimulation therapy programme for people with dementia: randomised controlled trial. The British Journal of Psychiatry, 183(3), 248-254.

Streater, A. J. (2015). Implementing maintenance cognitive simulation therapy (CST) in practice: a randomised controlled trial (RCT) of training and monitoring studies. (Doctoral dissertation, UCL (University College London)). 
Thomas, J., \& Harden, A. (2008). Methods for the thematic synthesis of qualitative research in systematic reviews. BMC Medical Research Methodology, 8, 45. https://doi.org/10.1186/1471-2288-8-45

Toh, H. M., Ghazali, S. E., \& Subramaniam, P. (2016). The acceptability and usefulness of Cognitive Stimulation Therapy for older adults with Dementia: A narrative review. International Journal of Alzheimer's Disease, 2016.Trivedi, P., \& Wykes, T. (2002). From passive subjects to equal partners. British Journal of Psychiatry, 181(6), 468-472. https://doi.org/10.1192/bjp.181.6.468

Vygotsky, L. S., (1978). Mind in Society: The Development of Higher Psychological Processes. Harvard University Press.

Wong, G. H., Yek, O. P., Zhang, A. Y., Lum, T. Y., \& Spector, A. (2018). Cultural adaptation of cognitive stimulation therapy (CST) for Chinese people with dementia: multicentre pilot study. International journal of geriatric psychiatry, $33(6), 841-848$.

Woods, B., Aguirre, E., Spector, A. E., \& Orrell, M. (2012). Cognitive stimulation to improve cognitive functioning in people with dementia. Cochrane Database of Systematic Reviews, (2).

Yates, L. A., Orrell, M., Spector, A., \& Orgeta, V. (2015). Service users' involvement in the development of individual Cognitive Stimulation Therapy (iCST) for dementia: a qualitative study. BMC geriatrics, 15(1), 4 . 


\section{Appendices}

Appendix A - Search Terms: January 2019

\begin{tabular}{|c|c|c|}
\hline Source & Search Strategy & $\begin{array}{c}\text { Articles } \\
\text { retrieved }\end{array}$ \\
\hline PsychINFO & $\begin{array}{l}\text { 1. exp VASCULAR DEMENTIA/ or exp } \\
\text { DEMENTIA/ or exp SEMANTIC DEMENTIA/ } \\
\text { or exp PRESENILE DEMENTIA/ or exp } \\
\text { DEMENTIA WITH LEWY BODIES/ or exp } \\
\text { SENILE DEMENTIA/ } \\
\text { 2. exp Delirium/ } \\
\text { 3. exp alzheimer's disease/ } \\
\text { 4. exp cognitive impairment/ } \\
\text { 5. dement*.mp } \\
\text { 6. Alzheimer*.mp } \\
\text { 7. Cognitive stimulation therapy.mp } \\
\text { 8. CST.mp } \\
\text { 9. } 7 \text { or } 8 \\
\text { 10. or/1-6 } \\
\text { 11. } 9 \text { and } 10\end{array}$ & 106 \\
\hline MEDLINE & $\begin{array}{l}\text { 1. Exp Dementia/ } \\
\text { 2. Alcoholic Korsakoff syndrome/ or huntington } \\
\text { disease/ or cognitive dysfunction/ } \\
\text { 3. Dement*.mp } \\
\text { 4. Alzheimer*.mp } \\
\text { 5. Exp Parkinsonian Disorders/ } \\
\text { 6. Parkinson*.mp } \\
\text { 7. Cognitive Stimulation Therapy.mp } \\
\text { 8. CST.mp } \\
\text { 9. } 7 \text { or } 8 \\
\text { 10. Or/1-6 } \\
\text { 11. } 9 \text { and } 10\end{array}$ & 496 \\
\hline EMBASE & $\begin{array}{l}\text { 1. Exp HIV associated dementia/ or exp multiinfarct } \\
\text { dementia/ or exp semantic dementia/ or exp Pick } \\
\text { presenile dementia/ or exp presenile dementia/ or } \\
\text { exp dementia/ or exp frontotermporal dementia/ } \\
\text { 2. Cognitive defect/ }\end{array}$ & 157 \\
\hline
\end{tabular}


3. Dement*.mp

4. Alzheimer*.mp

5. Vascular.mp

6. Parkinson disease/

7. "supranuclear palsy".mp

8. Parkinson*.mp

9. Cognitive stimulation therapy.mp

10. CST

11. Or/1-8

12. 9 or 10

13. 11 and 12

CINAHL 1. MH "Dementia +"

2. TX dement*

3. TX Alzheimer*

4. (MH "Delirium") OR (MH "Delirium, Dementia, Amnestic, Cognitive Disorders")

5. TX cognitive impairment

6. TX lewy* N2 bod*

7. TX deliri*

8. TX Parkinson*

9. "cognitive stimulation therapy"

10. TX cognitive stimulation therapy

11. "CST"

WebOfScience

TOPIC:((dement* OR alzheimer* OR "lew* bod*"

OR deliri* OR parkinson*)) ANDTOPIC: ((CST OR

"cognitive stimulation therapy"))

Timespan: All years. Indexes: SCI-EXPANDED, SSCI, A\&HCI, CPCI-S, CPCI-SSH, BKCI-S, BKCISSH, ESCI, CCR-EXPANDED, IC. 
Table 1. Summary of article characteristics and quality assessment

\begin{tabular}{|c|c|c|c|c|c|c|}
\hline $\begin{array}{l}\text { Author \& } \\
\text { Country }\end{array}$ & Code & Aims & $\begin{array}{c}\text { CST } \\
\text { Format }\end{array}$ & Sample (N) & $\begin{array}{c}\text { Qualitative } \\
\text { Methodology }\end{array}$ & Quality Assessment \\
\hline $\begin{array}{l}\text { Bertrand } \\
\text { et al. } \\
(2018)\end{array}$ & $\mathrm{BE}$ & $\begin{array}{l}\text { Understand issues of } \\
\text { implementing CST } \\
\text { for Brazilian } \\
\text { population }\end{array}$ & $\begin{array}{l}\text { CST } \\
\text { Cultural } \\
\text { adaptation }\end{array}$ & $\begin{array}{l}\mathrm{HCP}(9) \\
\text { Carers (15) } \\
\text { PWD (13) }\end{array}$ & $\begin{array}{l}\text { Focus groups } \\
\text { Individual interview } \\
\text { (semi-structured) }\end{array}$ & $\begin{array}{l}\text { Met } 7 / 10 \text { criteria } \\
\text { +ve: Detailed description of how } \\
\text { focus groups and interviews }\end{array}$ \\
\hline Brazil & & & & & FA & $\begin{array}{l}\text { were conducted including } \\
\text { reasoning for individual } \\
\text { interview use with PWD } \\
\text {-ve: Participants had no prior } \\
\text { experience of CST }\end{array}$ \\
\hline $\begin{array}{l}\text { Wong et } \\
\text { al. (2017) } \\
\text { Hong } \\
\text { Kong }\end{array}$ & $\mathrm{W}$ & $\begin{array}{l}\text { To investigate } \\
\text { feasibility and } \\
\text { cultural } \\
\text { appropriateness of } \\
\text { CST -HK }\end{array}$ & $\begin{array}{l}\text { CST } \\
\text { Cultural } \\
\text { adaptation }\end{array}$ & $\begin{array}{l}\text { Facilitators (12) } \\
\text { Carer (13) }\end{array}$ & $\begin{array}{l}\text { Focus groups } \\
\text { Individual interview } \\
\text { (Semi-structured) } \\
\text { FA }\end{array}$ & $\begin{array}{l}\text { Met } 6 / 10 \text { criteria } \\
\text { +ve: Clear indication of topic } \\
\text { guide, map of cultural issues and } \\
\text { associated amendments to } \\
\text { program } \\
\text {-ve: Missing main participant } \\
\text { group of PWD; not clear on how } \\
\text { many attended focus groups } \\
\text { versus interview }\end{array}$ \\
\hline $\begin{array}{l}\text { Kelly et al. } \\
\text { (2017) } \\
\text { Ireland }\end{array}$ & K & $\begin{array}{l}\text { To explore } \\
\text { personalised account } \\
\text { of the impact of CST } \\
\text { (supplement } \\
\text { quantitative data) }\end{array}$ & $\begin{array}{l}\text { CST } \\
\text { Cultural } \\
\text { adaptation }\end{array}$ & $\begin{array}{l}\text { PWD (4) } \\
\text { Carers (6) } \\
\text { Facilitators (4) }\end{array}$ & $\begin{array}{l}\text { Individual interview } \\
\text { (Semi-structured) } \\
\text { Analysis methodology } \\
\text { unclear }\end{array}$ & $\begin{array}{l}\text { Met } 4.5 / 10 \text { criteria. } \\
\text { +ve: Clear topic guide for } \\
\text { interview } \\
\text {-ve: Qualitative methods not } \\
\text { justified; No information on why }\end{array}$ \\
\hline
\end{tabular}


some participants did not take part in interviews; only brief description of analysis process.

\begin{tabular}{cclcc}
\hline $\begin{array}{l}\text { Bailey et } \\
\text { al. (2017) }\end{array}$ & BA & $\begin{array}{l}\text { Investigate impact of } \\
\text { CST on PWD and }\end{array}$ & CST & Carers (20) \\
impact of carer & & \\
UK & support group & & TA
\end{tabular}

Met 5/10 criteria

Individual interview (semi-structured)

TA +ve: Some description of analysis process; topic guided provided for interviews -ve: Recruitment strategy unclear; qualitative design not justified; ethics process unclear

\begin{tabular}{cll}
\hline Leung et & L & Understand \\
al. (2017) & perspectives of PWD \\
& and carers on mental \\
UK & stimulation and \\
& experiences of \\
& participating in iCST
\end{tabular}

iCST

PWD and Carer

Semi-structured
interview

FA dyads (23) Met 9/10 criteria

+ve: Separation of PWD and carer for interview and clear recruitment strategy; transparent interview guide; consideration of implication of recruitment strategy; more than one analyst -ve: Does not explicitly justify semi-structured interview use

\begin{tabular}{|c|c|c|c|c|}
\hline $\begin{array}{l}\text { Dickinson } \\
\text { et al. } \\
(2017)\end{array}$ & D & $\begin{array}{l}\text { Explore views and } \\
\text { experiences of staff } \\
\text { running CST in terms } \\
\text { of barriers and }\end{array}$ & CST & Facilitators (24) \\
\hline UK & & facilitators & & \\
\hline
\end{tabular}


clearly outlined; multiple

analysts

-ve: Methodology not justified

clearly

\begin{tabular}{|c|c|c|c|c|c|c|}
\hline $\begin{array}{l}\text { Yates et al. } \\
\text { (2015) } \\
\text { UK }\end{array}$ & $\mathrm{Y}$ & $\begin{array}{l}\text { Gain insight into } \\
\text { perception of mental } \\
\text { stimulation from } \\
\text { view of carers and } \\
\text { PWD }\end{array}$ & iCST & $\begin{array}{l}\text { PWD (28) } \\
\text { Carers (24) }\end{array}$ & $\begin{array}{l}\text { Focus group } \\
\text { Individual interview } \\
\text { (semi-structured) } \\
\text { TA }\end{array}$ & $\begin{array}{l}\text { Met } 8.5 / 10 \text { criteria } \\
\text { +ve: Clear topic guide and } \\
\text { description of data collection; } \\
\text { Continued assessment of consent } \\
\text { regarding recordings; examined } \\
\text { role of interviewer experience; } \\
\text { thorough analysis } \\
\text {-ve: specific methods not clearly } \\
\text { justified }\end{array}$ \\
\hline $\begin{array}{l}\text { Aguirre et } \\
\text { al. (2011) } \\
\text { UK }\end{array}$ & A & $\begin{array}{l}\text { To improve MCST } \\
\text { manual by attuning to } \\
\text { attitudes and } \\
\text { perceptions of user } \\
\text { needs }\end{array}$ & MCST & $\begin{array}{l}\text { PWD (17) } \\
\text { Carers (18) } \\
\text { Facilitators (13) }\end{array}$ & $\begin{array}{l}\text { Focus groups } \\
\text { TA }\end{array}$ & $\begin{array}{l}\text { Met } 8.5 / 10 \text { criteria } \\
\text { +ve: Clear description of } \\
\text { recruitment strategy; justification } \\
\text { of interview methodology; } \\
\text { reflection on interaction between } \\
\text { focus group members; discussed } \\
\text { contradictory data. } \\
\text {-ve: Not clear how consent was } \\
\text { gained; no provision of ethics } \\
\text { committee reference. }\end{array}$ \\
\hline $\begin{array}{l}\text { Spector et } \\
\text { al. (2011) }\end{array}$ & SP & $\begin{array}{l}\text { To investigate the } \\
\text { experience of CST as }\end{array}$ & CST & $\begin{array}{l}\text { PWD (17) } \\
\text { Carers (14) }\end{array}$ & $\begin{array}{l}\text { Focus group } \\
\text { Individual interview } \\
\text { (semi-structured) }\end{array}$ & Met $8.5 / 10$ criteria \\
\hline
\end{tabular}




\begin{tabular}{|c|c|c|c|c|}
\hline UK & $\begin{array}{l}\text { expressed in day to } \\
\text { day life }\end{array}$ & Facilitators (7) & FA & $\begin{array}{l}\text { +ve: Data saturation discussed; } \\
\text { data collection methods clear; } \\
\text { clear analysis procedure } \\
\text {-ve: Interview methodology not } \\
\text { explicitly justified; singular } \\
\text { analyst. }\end{array}$ \\
\hline $\begin{array}{l}\text { Streater et } \\
\text { al. (2015) }\end{array}$ & $\begin{array}{l}\text { To investigate staff's } \\
\text { perceptions on } \\
\text { delivery of MCST } \\
\text { and provide more in } \\
\text { depth understanding } \\
\text { of group processes } \\
\text { and outcomes. }\end{array}$ & Facilitators (15) & $\begin{array}{l}\text { Focus groups } \\
\text { TA }\end{array}$ & $\begin{array}{l}\text { Met } 9 / 10 \text { criteria } \\
\text { +ve: Justification of analysis } \\
\text { methodology and thorough } \\
\text { description of analysis } \\
\text { procedure; clear outline of } \\
\text { interview methodology; } \\
\text {-ve: Saturation of data not } \\
\text { discussed, sample majority } \\
\text { female; only one analyst }\end{array}$ \\
\hline
\end{tabular}

Codes are allocated to each study based on initial of first author.

Key: PWD = People with dementia HCP = Health Care Professionals; + ve = Positives; - ve = Negatives; CST = Cognitive Stimulation Therapy; MCST = Maintenance Cognitive Stimulation Therapy; iCST = Individual Cognitive Stimulation Therapy

FA = Framework analysis (Ritchie \& Spencer, 1993); TA = Thematic analysis (Braun \& Clarke, 2012) 
Table 2. Hierarchy of themes and coverage within the reviewed articles

\begin{tabular}{|c|c|c|c|c|c|c|c|c|c|c|c|c|}
\hline \multicolumn{3}{|c|}{ Themes } & BE & $\mathbf{W}$ & $\mathbf{K}$ & $\mathbf{B A}$ & $\mathbf{L}$ & D & $\mathbf{Y}$ & $\mathbf{A}$ & SP & ST \\
\hline \multirow{5}{*}{$\begin{array}{l}\text { Acceptability } \\
\text { and feasibility }\end{array}$} & \multicolumn{2}{|c|}{ Fitting service needs } & $\mathrm{x}$ & & & & & $\mathrm{x}$ & & & & $\mathrm{x}$ \\
\hline & \multirow{4}{*}{$\begin{array}{l}\text { Facilitators } \\
\text { and barriers }\end{array}$} & Carer engagement & $\mathrm{x}$ & & $\mathrm{X}$ & & & & & & $\mathrm{x}$ & $\mathrm{x}$ \\
\hline & & Resources & & & $\mathrm{x}$ & & & $\mathrm{x}$ & $\mathrm{x}$ & $\mathrm{x}$ & & $\mathrm{x}$ \\
\hline & & Training and experience & & & & & $\mathrm{x}$ & $\mathrm{x}$ & $\mathrm{x}$ & & & $\mathrm{x}$ \\
\hline & & Patient motivation & $\mathrm{x}$ & & & & $\mathrm{x}$ & & $\mathrm{x}$ & & & $\mathrm{x}$ \\
\hline \multirow{6}{*}{$\begin{array}{c}\text { Features of } \\
\text { CST }\end{array}$} & \multicolumn{2}{|c|}{ Mental stimulation } & $\mathrm{x}$ & & & & $\mathrm{x}$ & & $\mathrm{X}$ & $\mathrm{x}$ & & \\
\hline & \multicolumn{2}{|r|}{ Adaptability } & & $\mathrm{x}$ & & $\mathrm{x}$ & & & & $\mathrm{x}$ & & $\mathrm{x}$ \\
\hline & \multicolumn{2}{|c|}{ Being with others } & $\mathrm{x}$ & & & $\mathrm{x}$ & $\mathrm{x}$ & $\mathrm{x}$ & $\mathrm{x}$ & $\mathrm{x}$ & $\mathrm{x}$ & \\
\hline & \multicolumn{2}{|c|}{ Practical activities } & & $\mathrm{x}$ & & & $\mathrm{x}$ & & $\mathrm{x}$ & $\mathrm{x}$ & & \\
\hline & \multicolumn{2}{|c|}{ Relaxed environment } & & & & & & $\mathrm{x}$ & $\mathrm{x}$ & $\mathrm{x}$ & $\mathrm{x}$ & \\
\hline & \multicolumn{2}{|c|}{ Difficulty of sessions } & & & $\mathrm{X}$ & $\mathrm{x}$ & $\mathrm{x}$ & & $\mathrm{x}$ & & & $\mathrm{x}$ \\
\hline \multirow{7}{*}{ Key outcomes } & & Cognition & & & $\mathrm{x}$ & $\mathrm{x}$ & $\mathrm{x}$ & & $\mathrm{x}$ & & $\mathrm{x}$ & $\mathrm{x}$ \\
\hline & & Confidence & & & $\mathrm{x}$ & $\mathrm{x}$ & $\mathrm{x}$ & $\mathrm{x}$ & & $\mathrm{X}$ & $\mathrm{x}$ & $\mathrm{x}$ \\
\hline & & Enjoyment & & & $\mathrm{x}$ & $\mathrm{x}$ & $\mathrm{X}$ & & & & $\mathrm{x}$ & $\mathrm{x}$ \\
\hline & & Mood & & $\mathrm{x}$ & $\mathrm{x}$ & $\mathrm{x}$ & $\mathrm{x}$ & $\mathrm{x}$ & $\mathrm{x}$ & & $\mathrm{x}$ & $\mathrm{x}$ \\
\hline & \multicolumn{2}{|c|}{ Continued stimulation } & & & $\mathrm{x}$ & $\mathrm{x}$ & $\mathrm{x}$ & & & & $\mathrm{x}$ & $\mathrm{x}$ \\
\hline & \multicolumn{2}{|c|}{ Relationships } & & & & $\mathrm{x}$ & $\mathrm{x}$ & & & & $\mathrm{x}$ & \\
\hline & \multicolumn{2}{|c|}{ Making a difference } & & & $\mathrm{X}$ & & $\mathrm{X}$ & & & & $\mathrm{x}$ & $\mathrm{x}$ \\
\hline
\end{tabular}

Key: Checked boxes indicate that the study contributed to the corresponding theme. 